\title{
Along-dip segmentation of the 2011 off the Pacific coast of Tohoku Earthquake and comparison with other megathrust earthquakes
}

\author{
Kiyoshi Yomogida, Kazunori Yoshizawa, Junji Koyama, and Motohiro Tsuzuki \\ Earth and Planetary Dynamics, Graduate School of Science, Hokkaido University, Sapporo 060-0810, Japan
}

(Received April 11, 2011; Revised May 31, 2011; Accepted June 4, 2011; Online published September 27, 2011)

\begin{abstract}
We present some singular characteristics of the 2011 off the Pacific coast of Tohoku Earthquake in comparison with other megathrust earthquakes, such as the 1960 Chilean and the 2004 Sumatra-Andaman earthquakes. In addition to the conventional along-strike segmentation, along-dip segmentation of the fault area or subduction zone is an important feature for the Tohoku subduction zone, as indicated by the difference in background seismicity: virtually no seismicity in shallow segments but active with large events repeating in deep segments. The interaction between along-dip segments (deep and shallow segments) led to the great 2011 Tohoku earthquake. The along-dip segmentation results in plane or two-dimensional rupture propagation on a coseismic fault. Significant along-strike variability is also important for the 2011 Tohoku earthquake, with segments of both weak (e.g., slow or tsunami earthquakes) and strong plate couplings located adjacent to each other. In contrast, every segment appears to be with strong plate coupling for other megathrust earthquakes. One exception is the 1964 Alaska earthquake that shares a certain degree of common characteristics with the 2011 Tohoku earthquake: two distinct seismogenic zones along the dip direction of the trench, that is, the along-dip segmentation is noticeable. Significant along-strike variability also characterizes the activities in and around the subduction zone of the 1964 Alaska earthquake, including a creeping segment and a tsunami-earthquake segment.
\end{abstract}

Key words: Megathrust earthquake, along-dip segmentation, seismicity, along-strike variability, 2011 Tohoku earthquake.

\section{Introduction}

The 2011 off the Pacific coast of Tohoku, Japan, Earthquake of JMA magnitude 9.0 occurred on 11 March, 2011, in the most intensively investigated subduction zone in the world. With state-of-the-art seismic and geodetic observations in both land and sea floor, together with a relatively long documented history (up to 150 years in detail and 500 years in general) of large earthquakes, the official earthquake forecasting project of Japan issued, in early 2010, a specific probability (99\% within 30 years) of an earthquake of magnitude around 7.8 off Miyagi Prefecture. In contrast, the possibility of a megathrust earthquake of magnitude larger than 8.5 was not even discussed from a scientific point of view.

Megathrust earthquakes had been believed to occur commonly in a so-called Chilean-type subduction zone (e.g., Kanamori, 1977; Uyeda, 1982; Lay et al., 1982). In general, fault areas of megathrust earthquakes are very long (e.g., as long as $1,000 \mathrm{~km}$ in length along a trench) with dominant rupture propagation in the direction of a trench axis, unilateral in many cases, exciting large tsunamis. The seismicity preceding the 1960 Chilean earthquake was, for example, very low (e.g., Lay et al., 1982), implying nearly $100 \%$ coupling between overriding and young-buoyant sub-

Copyright (C) The Society of Geomagnetism and Earth, Planetary and Space Sciences (SGEPSS); The Seismological Society of Japan; The Volcanological Society of Japan; The Geodetic Society of Japan; The Japanese Society for Planetary Sciences; TERRAPUB.

doi:10.5047/eps.2011.06.003 ducting plates. That is, the strain accumulated at plate boundaries may be released only associated with megathrust earthquakes.

The 2011 Tohoku earthquake appears to lack these major characteristics of megathrust earthquakes of the Chileantype subduction zones although the number of examples is limited. First, we point out several singular characteristics of the 2011 Tohoku earthquake. We consider segmentation of seismogenic zones in the dip direction of the megathrust boundary while segmentation in the strike direction only has been considered for most subduction zones. For the 2011 Tohoku earthquake, we also notice remarkable along-strike variability in the behavior of seismogenic zones, reflecting highly spatially heterogeneous plate coupling. Next, we compare these characteristics with other earthquakes. While the 1960 Chilean and 2004 Sumatra earthquakes are different from the 2011 Tohoku earthquake, we find some similarity in several characteristics between the 1964 Alaska earthquake and the 2011 Tohoku earthquake.

\section{Along-dip Segmentation of the 2011 Tohoku Earthquake}

In the subduction zone along the Japan Trench located off the coast of the Tohoku district, there are segments with distinct seismic activities, as shown in Fig. 1(a), superposed on the background seismicity map of Uchida et al. (2009). The occurrence pattern of large earthquakes in the past leads to these segments between coastal areas and the trench axis, 

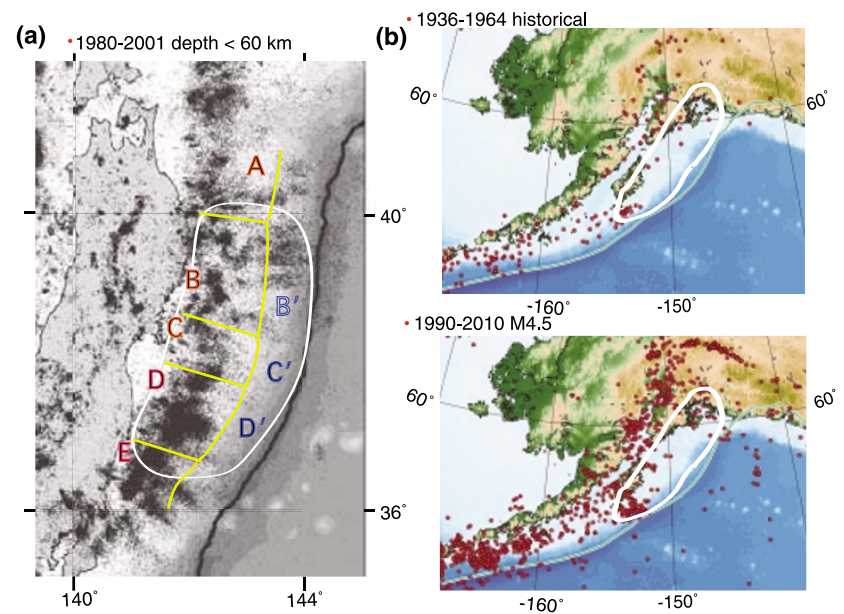

Fig. 1. Seismicity in subduction zones of (a) Tohoku, eastern Japan, and (b) Alaska with fault areas of the 2011 and 1964 earthquakes in white, compiled by Tohoku University (after Uchida et al. (2009)) and the U.S. Geological Survey, respectively. In eastern Japan, earthquakes in 1980-2001 at depths shallower than 60 $\mathrm{km}$ are plotted. The segmentation of seismogenic zones are shown in (a), following the national project of disaster prevention of Japan (http://www.j-shis.bosai.go.jp/?lang-en). In Alaska, earthquakes before the 1964 earthquake of magnitude over 5.0 are plotted from 1935 to 1964 and magnitude over 4.5 from 1990 to 2010.

which the official earthquake forecasting project of Japan has defined (e.g., http://www.j-shis.bosai.go.jp/?lang=en). There had been no earthquakes larger than magnitude 8.0 in this area for more than 1,000 years except for a large tsunami earthquake in 1896 in Segment B' and a normalfault event in 1933 in the outer-rise area. All the earthquakes in the past occurred within each segment, exhibiting different characteristics from one to the other. There were no earthquakes that caused serious casualties in Segment B (e.g., Kanamori, 1977), and no large earthquakes occurred in Segment D over 500 years except for a series of earthquakes of magnitude less than 7.8 in 1938 (Abe, 1977). In contrast, there were earthquakes of magnitude of 7.5 to 7.8 in Segment $\mathrm{C}$ repeated with an interval of several tens of years, consistent with its plate convergence rate (about 8.6 $\mathrm{cm} /$ year). That is why the official earthquake forecast was released for this segment, as mentioned in the Introduction.

In most subduction zones, particularly if well investigated, segmentation is introduced in the strike direction of the trench, for example, Segments A, B, C, and D in Fig. 1(a). The interrelation among plural segments was essential in the occurrence of megathrust earthquakes in the past. The distribution of segments involved in the 2011 Tohoku earthquake is clearly different from such previous cases. Results of near-field tsunami records strongly support anomalously large slips in Segment $C^{\prime}$ (e.g., Maeda et al., 2011). During the 2011 Tohoku earthquake, segments were interrelated not only in the strike direction but also in the dip direction of the trench, such as Segments $\mathrm{C}$ and $\mathrm{C}^{\prime}$. As shown above, we can define a series of segments in a shallow region up-dip, and another series of segments in a deep region down-dip. In this paper, we call this separation between shallow and deep regions "along-dip segmentation". In other subduction zones, segmentation is primarily

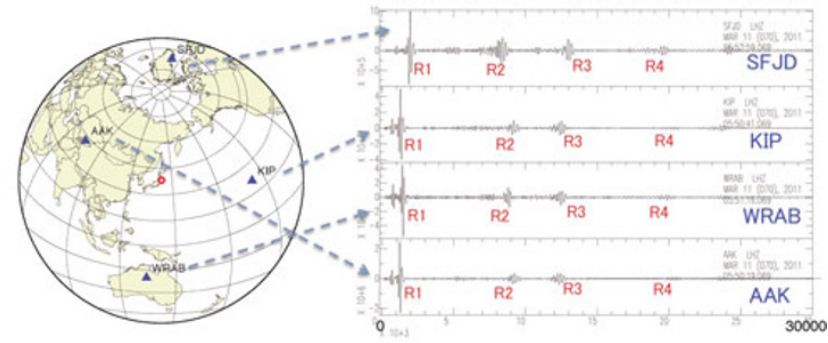

Fig. 2. Multi-orbit long-period surface waves for the 2011 off the Pacific coast of Tohoku Earthquake. Waveforms are vertical component with a bandpass filter from 3 to $10 \mathrm{mHz}$. Amplitudes decay systematically in time at stations in any directions from the source, representing a point-like source.

along-strike, but the along-dip segmentation and the interrelation between deep and shallow segments appear to have played an essential role in the 2011 Tohoku earthquake.

\subsection{Seismicity}

Figure 1(a) leads us to the introduction of along-dip segmentation for the 2011 Tohoku earthquake, in order to describe the seismicity preceding it (Uchida et al., 2009). Even taking the limitation of event detectability only by observations on land into consideration, we can see virtually no seismicity in segments close to the trench such as Segments $C^{\prime}$ and $D^{\prime}$. Segments $C^{\prime}$ and $D^{\prime}$ were believed to be always aseismic because of the lack of historical documents about large earthquakes, at least over the past 1,000 years.

Extremely large slips are estimated in Segment $C^{\prime}$ for the 2011 Tohoku earthquake by not only near-fault tsunami data (e.g., Maeda et al., 2011) but also by high-frequency seismic waves up to $0.5 \mathrm{~Hz}$ (e.g., Honda et al., 2011). The lack of background seismicity in Segment $C^{\prime}$ (and probably a part of Segment $\mathrm{D}^{\prime}$ ) can therefore be attributed to the seismic gap related to the 2011 Tohoku earthquake. Nevertheless, this seismic gap, illustrated in Fig. 1(a), could not have been recognized seriously probably because many researchers just followed the conventional along-strike segmentation.

\subsection{Teleseismic data}

While there are near-fault data unprecedentedly rich in both quality and quantity for the 2011 Tohoku earthquake, other megathrust earthquakes (e.g., 1960 Chile, 1964 Alaska and 2004 Sumatra) could be studied only with teleseismic data in general. For comparison purposes, we here point out features of this earthquake with teleseismic data which are also available for other earthquakes. As an example, Fig. 2 shows vertical-component seismograms at four stations in various directions from the source region. These records are multi-orbit Rayleigh waves filtered with a bandpass filter from 3 to $10 \mathrm{mHz}$. It is widely known that the excitation of surface waves is enhanced in the direction of rupture propagation, for example, in the north for the 2004 Sumatra earthquake (e.g., Ammon et al., 2005; Yoshizawa, 2006). Since the trench axis for the 2011 Tohoku earthquake is nearly in the NS direction, we might expect some difference in waveforms between seismograms at stations in the north (e.g., SFJD) and the south (WRAB), which is 


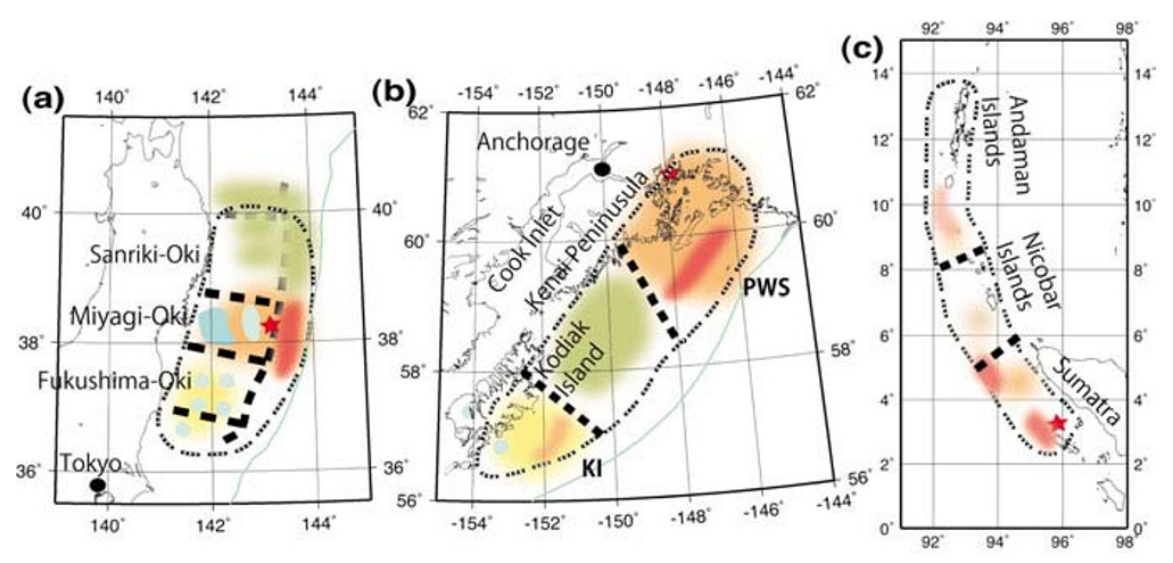

Fig. 3. Comparison of schematic views of source processes and related seismic activities for the (a) 2011 Tohoku, (b) 1964 Alaska, and (c) 2004 Sumatra earthquakes. Epicenters are shown by red stars, areas of major seismic moment release by orange patches and possible tsunami-excitation areas by red patches. In (a), the thick dashed lines represent the segments similar to Fig. 1(a), slow earthquakes including the 1896 great tsunami earthquake close to the trench are shown by four green patches, recent large Miyagi-Oki earthquakes by two blue patches, and five moderate Fukushima-Oki earthquakes in 1938 by light blue circles with a region of large excitation of high-frequency waves (Honda et al., 2011) and many aftershocks in light yellow. In (b), the orange patch is called the Prince William Sound asperity (PWS), two blue circles near the Kodiak Island represent intraplate earthquakes in 1999 and 2001 with the Kodiak Island asperity (KI) in yellow, and a creeping segment between them is shown in green (Ratchkovski and Hansen, 2001; Freymueller et al., 2008). In (c), the areas of large slips are estimated by teleseismic body waves in orange (Ammon et al., 2005) and those estimated by tsunami waveforms in red (Tanioka et al., 2006) with the three along-strike segments proposed by Lay et al. (2005).

not the case. This observation suggests that the source of the 2011 Tohoku earthquake is adequately represented by a point source. No dominant rupture propagations in either strike or dip direction resulted in the point-like character.

\subsection{Along-strike variability}

In addition to the along-dip segmentation of the Tohoku subduction zone, let us now focus on the conventional along-strike segmentation in this subduction zone. As explained above, no large earthquakes have been documented in Segment D, except for a series of five earthquakes of magnitude up to 7.8 in 1938 (Abe, 1977), as shown by light blue circles in Fig. 3(a). Plate coupling in Segment D is estimated to be weak, particularly because of the occurrence of two normal-fault intra-plate earthquakes in 1938. New GPS/acoustic seafloor observation also confirmed weak plate coupling in Segment D and/or D' (Matsumoto et al., 2008). The segment of Sanriku-Oki (Segment B) has no large historical earthquakes. Kawasaki et al. (2001) recently identified several slow earthquakes in Segment B, as shown by green patches in Fig. 3(a), implying its very weak plate coupling.

Segment C, where the epicenter of the 2011 Tohoku earthquake is located, may have a potential to generate a large earthquake, as already mentioned, while its adjacent two segments, Segments B and D, do not. Following a recent popular term in seismology, we may call Segment C a segment with strong asperities while Segments B and $\mathrm{D}$ have no, or very minor, asperities. This dramatic variability among along-strike segments, including segments of weak plate coupling, is very striking. Thus, the idea that no megathrust earthquakes are likely in the Tohoku subduction zone appeared reasonable before 2011. The interaction between deep and shallow segments, Segments $\mathrm{C}$ and $\mathrm{C}^{\prime}$, is considered essential for causing an $M 9$ earthquake; their combined slips may have triggered large slips in adjacent along-strike segments (Segments B and D) of relatively weak plate coupling where no large slips can happen if they fail by themselves.

Figure 3(a) summarizes a schematic view of the above singular characteristics of the 2011 Tohoku earthquake. Not only the along-dip segmentation but also the above variability within along-strike segments characterize this subduction zone.

\section{Comparison with Other Megathrust Earth- quakes}

We have pointed out singular characteristics of the 2011 Tohoku earthquake. Now let us compare them with characteristics of other examples, particularly with three recent events: the 1960 Chilean, 1964 Alaska and 2004 Sumatra earthquakes.

\subsection{Seismicity}

In general, plate coupling is believed to be strong and the background seismicity is known to have been very low in the along-strike segment for other megathrust earthquakes (e.g., Kanamori, 1977; Lay et al., 1982): the 1960 Chile, the 2004 Sumatra, and the historically-repeating Nankai trough megathrust earthquakes in southwest Japan such as the 1707 Hoei earthquake (e.g., Okano and Kimura, 1979). This marks a very clear contrast with the 2011 Tohoku earthquake, as shown in Fig. 1(a): background seismicity is observed in all the deep segments such as Segments B, $\mathrm{C}$ and $\mathrm{D}$, but weak or no seismicity is observed in shallow segments such as Segments $C^{\prime}$ and $D^{\prime}$.

Figure 1(b) shows earthquake distributions before and after the 1964 Alaska earthquake. Along the Alaska-Aleutian subduction zone, earthquakes occur uniformly in the seismogenic zone except for a shallow part of the fault area of the 1964 earthquake. This implies that the subduction zone of the 1964 Alaska earthquake is segmented in the alongdip direction. The shallow segments seem to have been ruptured during the 1964 Alaska earthquake (e.g., Freymueller et al., 2008), although this cannot be confirmed because sufficient near-coast or ocean bottom observations were not 
available. Doser et al. $(2006,2008)$ studied the seismicity in this area very carefully, but there are no interplate shallow events before and after the earthquake although they did not conclude this explicitly. Thus, along-dip segmentation similar to that seen for the Tohoku subduction zone seems also to be seen for the 1964 Alaska subduction zone.

One may argue that the difference in seismicity simply originates from the detection capability of events between deep and shallow segments in other cases. Although the zone is very narrow for the 2004 Sumatra earthquake, as shown in Fig. 3(c), no such along-dip segmentation is obvious; it is not obvious for the 1960 Chilean earthquake and the Nankai trough in Japan. If along-dip segmentation exists in these subduction zones, the spatial resolution of seismicity is now sufficient to identify it. Thus, the above two cases (i.e., Tohoku and Alaska) can be considered to be exceptional.

\subsection{Teleseismic and other data}

The source process of the 2004 Sumatra earthquake was estimated from teleseismic, tsunami and geodetic data. Figure 3(c) shows the areas of large slips estimated from teleseismic data in orange (Ammon et al., 2005) and those from tsunami data in red (Tanioka et al., 2006). Three along-strike segments (Sumatra, Nicobar and Andaman segments) are proposed by another study on tsunami excitation (Lay et al., 2005). Although different results have been proposed and there is a certain degree of variability, the distribution of slips is more-or-less one-dimensional or linear; the areas of large slips also extend in the strike direction for the 1960 Chilean earthquake (e.g., Moreno et al., 2009). The directivity of excitation of long-period surface waves is very strong for these examples, implying the dominance of unilateral and one-dimensional rupture propagations.

In the case of the 1964 Alaska earthquake, Kanamori (1970) investigated the excitation characteristics. In particular, he found its directivity or rupture propagation to have a component perpendicular to the trench, from deep to shallow. Ruff and Kanamori (1983) found that its major moment release was around the epicenter (the orange area in Fig. 3(b)), using core-diffracted $P$ waves; this feature is very simple compared with other large earthquakes. Using tsunami and geodetic data, Johnson et al. (1996) determined a slip distribution on the fault, retrieving two areas of large slips or asperities: a very large one at the northeastern end called the Prince William Sound asperity and a much smaller one at the sorthwestern end called the Kodiak asperity, as represented by PWS and KI in Fig. 3(b). Ichinose et al. (2007) located these asperities near the trench, similar to the major tsunami excitation area of the 2011 Tohoku earthquake. The PWS asperity appeared to correspond to the area of the major moment release of Ruff and Kanamori (1983). Large slips near the trench appear to have been related to the deep-to-shallow rupture propagation component found by Kanamori (1970), implying the interrelation of along-dip segments.

\subsection{Contrast of along-strike segments}

Except for the aftershock activities, the background seismic activities are minor in the entire subduction zones of the 1960 Chilean and the 2004 Sumatra earthquakes. In contrast, activities in adjacent along-strike segments of the 1964 Alaska earthquake greatly vary. For example, Kanamori (1972) studied a large tsunami earthquake of 1946, similar to a large 1896 tsunami earthquake to the north of the 2011 Tohoku earthquake (Segment B'). Moreover, there were two earthquakes of $M 7$ in 1999 and 2001 in the Kodiak Island region (light blue circles in Fig. 3(b)). They are normal-fault earthquakes inside the subducting plate (Ratchkovski and Hansen, 2001), similar to the events of 1938 in Segment D of the Tohoku subduction zone. We cannot find any segments with such a seismogenic pattern for the 1960 Chilean earthquake, and this is probably also the case for the 2004 Sumatra earthquake. Seismicity was low before 2011 but aftershocks of the 2011 earthquake have been active in Segment D, compared with Segment C (active even before 2011), analogous to the temporal pattern of seismicity in the KI asperity: weak before, but enhanced after, the 1964 earthquake (Doser et al., 2006).

There is also a creeping segment with slow-slip events in a deep part between the two asperities (PWS and KI) of the 1964 Alaska earthquake (a green patch in Fig. 3(b)). Freymueller et al. (2008) concluded dramatic variability along the strike of the trench over a short distance, and even pointed out its similarity to the Tohoku subduction zone. The Tohoku plate boundary seems to be mechanically very heterogeneous, so is the Alaska-Aleutian plate boundary while no such evidence has been found for the 1960 Chilean and the 2004 Sumatra plate boundaries.

\section{Conclusions}

In this paper, we point out several singular characteristics of the 2011 Tohoku earthquake as compared with other megathrust earthquakes, as summarized in Fig. 3 and Table 1. First, we emphasize along-dip segmentation of a subduction zone with shallow and deep segments, whereas only along-strike segmentation has previously been considered for subduction zones. The background seismicity in the shallow segment in the case of the 2011 Tohoku earthquake had been very low, but large slip occurred there in this megathrust earthquake, suggesting that plate coupling there was strong. In contrast, the deep segment of the 2011 Tohoku earthquake had been seismically active with large repeating earthquakes of about $M 7.5$. Prior to the occurrence of a megathrust earthquake, a subduction zone of along-dip segmentation does not, therefore, look much different from subduction zones of along-strike segmentation having no record of megathrust earthquakes, with which the Tohoku subduction had been compared.

Another important characteristic of the 2011 Tohoku earthquake is the dramatic variability in the along-strike segments. The seismicity of the Tohoku subduction zone has been active in Segment C, while virtually no large earthquakes have occurred in Segments B and D over the last 500 years except for a few events in 1938 (Abe, 1977). A large tsunami earthquake in 1896 in a shallow segment $\mathrm{B}^{\prime}$ (Kanamori, 1972) and slow or aseismic slip events in Segment B (Kawasaki et al., 2001), as shown by green patches in Fig. 3(a), indicate weak plate coupling in Segments B and $\mathrm{B}^{\prime}$. Segments $\mathrm{C}$ and $\mathrm{C}^{\prime}$ appeared to have slipped significantly during the 2011 Tohoku earthquake from both tsunami (e.g., Maeda et al., 2011) and high-frequency seis- 
Table 1. Comparison of two types of megathrust earthquakes.

\begin{tabular}{c|cc}
\hline & Tohoku & Chile \& Sumatra \\
\hline Fault geometry & wide & elongated \\
Along-dip segmentation & distinct & none \\
Rupture propagation & plane & linear \\
Along-strike variability & very strong & minor \\
\hline
\end{tabular}

mic waves (e.g., Honda et al., 2011), implying very strong plate coupling although their background seismic patterns are quite different from each other.

No along-dip segmentation is obvious in the subduction zones of the 1960 Chilean and the 2004 Sumatra earthquakes. In contrast, the background seismicity for the 1964 Alaskan earthquake indicates along-dip segmentation, as shown in Fig. 1(b). In addition, the characteristics of the three proposed along-strike segments in Fig. 3(b) (Johnson et al., 1996; Freymueller et al., 2008) are highly different from each other, including their pre- and post-seismic activities (Doser et al., 2006, 2008). There was a large tsunami earthquake in 1946 to the west of the 1964 earthquake, characterizing this subduction zone (extending west beyond the rupture zone of the 1964 earthquake) as the one with dramatic along-strike variability (Freymueller et al., 2008). This variability is similar to that of the Tohoku subduction zone but different from the others.

Along-dip segmentation is a fundamental feature of the Tohoku subduction zone, and it is important to understand the seismic behavior of both up-dip and down-dip segments. Kanamori et al. (2006) pointed out the deficiency of cumulative seismic slip in comparison with the convergence rate of the subducting Pacific plate. The plate motion must be taken up by either large megathrust earthquakes, tsunami earthquakes (Kanamori, 1972) or aseismic or slow events (e.g., Kawasaki et al., 2001). During the 2011 Tohoku earthquake the interaction between the down-dip segment $\mathrm{C}$ and the up-dip segment $\mathrm{C}^{\prime}$ caused unusually large slip in the up-dip segment which resulted in an $M 9$ earthquake. This type of interaction between the down-dip and up-dip segments may play an important role in other subduction zones.

Acknowledgments. Ryou Honda and Takuto Maeda kindly and promptly provided us with their preliminary results on the 2011 Tohoku earthquake, which inspired us to confirm the importance of shallow segments. Yuuichiro Tanioka kindly showed us the tsunami data of the 1964 Alaska earthquake. Many useful and constructive comments by the editor (Hiroo Kanamori), Larry Ruff and one anonymous referee are greatly appreciated. We thank IRIS DMC for providing us with the data from Global Seismographic Network.

\section{References}

Abe, K., Tectonic implications of the large Shioya-Oki earthquakes of 1938, Tectonophysics, 41, 269-289, 1977.

Ammon, C. J. et al., Rupture process of the 2004 Sumatra-Andaman earthquake, Science, 308, 1133-1139, 2005.

Doser, D. I., A. M. Veilleux, C. Flores, and W. A. Brown, Changes in seismic-moment rates along the rupture zone of the 1964 Great Alaska earthquake, Bull. Seismol. Soc. Am., 96, 1545-1550, doi:10.1785/0120050194, 2006.

Doser, D. I., A. de la Prena, and A. M. Veilleux, Seismicity of the Prince William Sound region and its relation to plate structure and the 1964
Great Alaska earthquake, in Active Tectonics and Seismic Potential in Alaska, edited by J. T. Freymueller, P. T. Haeussler, R. L. Wesson, and G. Ekstrom, 431 pp., Geophysical Monograph Series, 179, 201-214, AGU, 2008.

Freymueller, J. T. et al., Active deformation processes in Alaska, based on 15 years of GPS measurements, in Active Tectonics and Seismic Potential in Alaska, edited by J. T. Freymueller, P. T. Haeussler, R. L. Wesson, and G. Ekstrom, 431 pp., Geophysical Monograph Series, 179, 1-41, AGU, 2008.

Honda, R., Y. Yukutake, H. Ito, M. Harada, T. Aketagawa, A. Yoshida, S. Sakai, S. Nakagawa, N. Hirata, K. Obara, and H. Kimura, A complex rupture image of the 2011 off the Pacific coast of Tohoku Earthquake revealed by the MeSO-net, Earth Planets Space, 63, this issue, 583588, 2011.

Ichinose, G., P. Somerville, H. K. Thio, R. Graves, and D. O'Connell, Rupture process of the 1964 Prince William Sound, Alaska, earthquake from the combined inversion of seismic, tsunami, and geodetic data, $J$. Geophys. Res., 112, B07306, doi:10.1029/2006JB004728, 2007.

Johnson, J. M., K. Satake, S. R. Holdahl, and J. Sauber, The 1964 Prince William Sound earthquake: joint inversion of tsunami and geodetic data, J. Geophys. Res., 101, 523-532, 1996.

Kanamori, H., The Alaska earthquake of 1964: Radiation of long-period surface waves and source mechanism, J. Geophys. Res., 75, 5029-5040, 1970.

Kanamori, H., Mechanism of tsunami earthquakes, Phys. Earth Planet. Inter., 6, 346-359, 1972.

Kanamori, H., Seismic and aseismic slip along subduction zones and their tectonic implications, in Island Arcs, Deep Sea Trenches and Back-arc Basins, edited by M. Talwani and W. C. Pitman, III, 470 pp., 163-174, AGU, 1977.

Kanamori, H., M. Myazawa, and J. Mori, Investigation of the earthquake off Miyagi prefecture with historical seismograms, Earth Planets Space, 58, 1533-1541, 2006.

Kawasaki, I., Y. Asai, and Y. Tamura, Space-time distribution of interplate moment release including slow earthquakes and the seismo-geodetic coupling in the Sanriku-oki region along the Japan trench, Tectonophysics, 330, 267-283, 2001.

Lay, T., H. Kanamori, and L. Ruff, The asperity model and the nature of large subduction zone earthquakes, Earthq. Predict. Res., 1, 3-71, 1982. Lay, T. et al., The great Sumatra-Andaman earthquake of 26 December 2004, Science, 308, 1127-1133, 2005.

Maeda, T., T. Furumura, S. Sakai, and M. Shinohara, Significant tsunami observed at ocean-bottom pressure gauges during the 2011 off the Pacific coast of Tohoku Earthquake, Earth Planets Space, 63, this issue, 803-808, 2011.

Matsumoto, Y. et al., Weak interplate coupling beneath the subduction zone off Fukushima, NE Japan, inferred from GPS/acoustic seafloor geodetic observation, Earth Planets Space, 60, e9-e12, 2008.

Moreno, M. S., J. Bolte, J. Klotz, and D. Melnick, Impact of megathrust geometry on inversion of coseismic slip from geodetic data: Application to the 1960 Chile earthquake, Geophys. Res. Lett., 36, L16310, doi:10.1029/2009GL039276, 2009.

Okano, K. and S. Kimura, Seismicity characteristics in Shikoku in relation to the great Nankai earthquakes, J. Phys. Earth, 27, 373-381, 1979.

Ratchkovski, N. A. and R. A. Hansen, Sequence of strong intraplate earthquakes in the Kodiak Island region, Alaska in 1999-2001, Geophys. Res. Lett., 28, 3729-3732, 2001.

Ruff, L. and H. Kanamori, The rupture process and asperity distribution of three great earthquakes from long-period diffracted P-waves, Phys. Earth Planet. Inter., 31, 202-230, 1983.

Tanioka, Y., Yudhicara, T. Kusunose, S. Kathiroli, Y. Nishimura, S. Iwasaki, and K. Satake, Rupture process of the 2004 great SumatraAndaman earthquake estimated from tsunami waveforms, Earth Planets Space, 58, 203-209, 2006.

Uchida, N., J. Nakajima, A. Hasegawa, and T. Matsuzawa, What controls interplate coupling?: Evidence for abrupt change in coupling across a border between two overlying plates in the NE Japan subduction zone, Earth Planet. Sci. Lett., 283, 111-121, 2009.

Uyeda, S., Subduction zones: An introduction to comparative subductology, Tectonophysics, 81, 133-159, 1982.

Yoshizawa, K., Multi-orbit surface wave generated by the 2004 Sumatra earthquake, Geophys. Bull. Hokaido Univ., 69, 15-21, 2006 (in Japanese with English abstract).

K. Yomogida (e-mail: yomo@mail.sci.hokudai.ac.jp), K. Yoshizawa, J. Koyama, and M. Tsuzuki 